\title{
ALGUNAS CONSIDERACIONES SOBRE DERECHO PENAL Y CONSTITUCION
}

\author{
José María Escrivá Gregori \\ (Universidad de Barcelona)
}

El trabajo trata de esclarecer algunas vinculaciones entre la Constitución y el Derecho penal. Tras analizar los rasgos característicos de las reformas penales en el periodo de transición política hasta la Constitución, en las que priman las notas de dispersión y de sujeción a la coyuntura política, estudia las funciones derivadas de la Constitución en el ámbito penal (en el campo práctico, en el de la política penal y en el doctrinal) y las del Derecho penal (protección de bienes jurídicos, inhibición de conductas, resolución de conflictos sociales, referencia al control social) y analiza en concreto algunos problemas que presenta la ponderación entre cierras normas penales ordinatias y otras normas constitucionales explícitas o implícitas: en materia de ley penal (el principio de legalidad y la admisión de la analogia in bonam partem), en la teoría del delito (afectación de bienes jurídicos, principio de culpabilidad) y en la teoría de la pena (límites de la pena, prevención especial, prevención general, función psicológico-satisfactiva y resolución de conflictos). Finalmente, se destaca la posibilidad de una dogmática progresiva en base a la Constitucióa y la importancia de las declaraciones fundamentales de los dos primeros párrafos del artículo 1 de la misma. 


\section{INTRODUCCION}

La vinculación existente entre la Constitución y el Derecho penal es algo evidente. Históricamente, la elaboración de nuevos códigos penales ha ido precedida de cambios políticos que tuvieron su tepercusión en la esfera penal como ponen de relieve los recientes estudios de Barbero Santos y Casabó Ruiz. Por referimos sólo al siglo $\mathrm{xx}$, las fechas de tales códigos (1928, 1932 y 1944, con sus posteriores revisiones, refundiciones y teformas) son bien elocuentes a los efectos de indicannos los diversos sistemas políticos en que fueton promulgados. Ello resulta ciertamente explicable, puesto que, por una parte, la pena puede considerarse como el recurso más poderoso del Estado y, por otra, las diversas situaciones politicas constituyen a su vez diferentes bases de partida para politicas penales muy distintas. Es decir, la política que el Estado realiza, fundamentalmente a través de la conminación de sanciones penales para ciertas conductas, dependerá en gran medida del presupuesto político del que el propio Estado parte. Cuando ese presupuesto viene plasmado en una constitución democráticamente elaborada y aprobada, las diferencias con una política derivada de un régimen autocrático suelen llevar a la promulgación de un nuevo Código penal y viceversa.

En España, la reciente Constitución de 1978 supone la plasmación al máximo nivel jurídico-político de un nuevo régimen político democrático. Un próximo Código penal, es de esperat, traducirá al ámbito penal las nuevas directrices constitucionales, aunque ya antes de la Constitución ${ }^{2}$

1. Cfr. Barbero Santos, Politica y Derecho Penal en España (Madrid: Tucar, 1977). Casabó Ruiz, Estudios preliminares a los proyectos de códigos penales de 1830, 1831, de Sainz de Andino, 1834, 1939 y Anteproyecto de 1938 de FET y de las JONS (5 tomos), (Murcia: Universidad de Murcia, 1978).

2. Vid., para la etapa posterior a la Ley para la Reforma Política aprobada por referéndum de 15 de diciembre de 1976, Vives Anton, «Reforma política y Derecho penal», Cuadernos de Politica criminal, 1 (1977); pp. 73 y ss. Para la situación previa 
fueron necesarias reformas parciales en el indicado ámbito como avances imprescindibles en el proceso de transición política del régimen autocrático al democrático. Hay que tener presente al respecto que la determinación de cuáles son los bienes jurídicos dignos de protección penal y frente a qué ataques, vendrá dada por una política penal, que, en una sociedad democrática, dependerá de la imposición por medios democtáticos de determinados critetios sobte otros. De ahí que dicha determinación requiere partir de una premisa: la legitimidad democrática de la política penal a llevar a cabo. En los regímenes políticos autocráticos esa función no puede ser cumplida de una manera completa por estar sujeta la política penal, en particular en determinadas parcelas de comportamientos, a la predominante política autocrática.

\section{TRANSICION POLITICA Y DERECHO PENAL EN LA ETAPA PREVIA A LA CONSTITUCION}

Las características de la repercusión en el ámbito penal del cambio político recientemente operado en España ${ }^{3}$ cabe resumirlas del siguiente modo:

1. Una primera etapa a destacar sería la comprendida entre el acceso del tey Juan Catlos a la Jefatura del Estado y las elecciones generales a diputados y senadores celebradas el 15 de junio de 1977. Esta etapa se caracteriza por la nota de transitoriedad preelectoral, es decir, por no haberse asentado todavía un régimen político democrático ni haber tenido ocasión de configurar mediante unas elecciones el organismo fundamental de una democracia: el Parlamento. En la esfera penal, los rasgos característicos del indicado período podtían sintetizarse en dos: a) una cierta toterancia en la aplicación de la ley en aquellos supuestos más afectados por la transición política, tolerancia que conlleva situaciones de inseguridad jurídica por la subsistencia de la legislación anterior con leves retoques a partir de ciertos momentos; $b$ ) una gran dispersión legislativa, deudora de la coyuntura política y que supone actuaciones en ocasiones repetitorias por no alcanzarse inicialmente los objetivos propuestos. Así sucede, por ejemplo, en relación a las medidas de gracia, que no consiguen de entrada

\footnotetext{
a dicha Ley: Quintcro Olivares, Represión penal y Estado de Derecho (Barcelona: Dirosa, 1976), pp. 60 y ss.

3. Vid. Escrivá Gregori, "Cambio político y reforma penai en la España actual: análisis general», Doctrina Penal 3 (Buenos Aires, 1978), pp. 627 y ss.
} 
la «reafirmación de los propósitos de convivencia solidaria y pacífica entre todos los españoles» (introducción del Decreto de 25 de noviembre de 1975 , «por el que se concede indulto general con motivo de la proclamación de su Majestad Don Juan Carlos de Borbón como Rey de España») y requieren los ulteriores Real Decreto-Ley de 30 de julio de 1976 «sobre amnistía” y Real-Decreto de 14 de marzo de 1977 sobre indulto general. También son signo visible de esa dispersión antes indicada las modificaciones en el Código penal y leyes penales especiales, destacando la modificación del Código de 19 de julio de 1976 que afecta a determinados artículos relativos a los derechos y libertades públicas y el Decreto-Ley de 1 de abril de 1977 que afecta a la regulación de la libertad de expresión. En tos aspectos procesales y de organización de la Administración de justicia cabe destacar la permanencia del privilegio que para los funcionarios de policía respecto al resto de ciudadanos supone el llamado «fuero policial” y el Real Decreto-Ley de 4 de enero de 1977 por el que se crea la Audiencia Nacional con sede en Madrid sin entrar en una más completa remodelación de la Administración de justicia.

2. Una segunda etapa abarcaría el período posterior al 15 de junio de 1977 y anterior a la Constitución. Está matcada por la nota de preconstitucionalidad y por el inicio del funcionamiento de los órganos parlamentarios: Congreso y Senado. Aunque supone ya un «rodaje» en el funcionamiento de instituciones propias de una democracia parlamentaria, es una etapa puente también, en la medida en que encuentra sus -limitaciones en la propia situación de preconstitucionalidad. Durante este período la política penal sigue caracterizándose por su dispersión y por la vinculación a la oportunidad politica del momento o a la futura rentabilidad electoral. Este factor de la rentabilidad electoral es de destacar en cuanto que su aparición está conectada al cambio en el sistema político y, por tanto, no eta posible en el régimen anterior. Dicha dispersión, sin embargo, aparece matizada por dos hechos: la amnistía por actos de intencionalidad política concedida por Ley de 15 de octubre de 1977 y por el llamado Pacto de la Moncloa, que supone un compromiso legislativo entre diversas fuerzas políticas y que afecta, entre otros, a diversos aspectos de la esfera penal que no es posible aquí detallar. 


\section{DISCREPANCIA DE ORIGEN ENTRE CODIGO PENAL Y CONSTITUCION}

Nos encontramos, pues, en la actualidad, con una situación en que la Constitución y las fuentes normativas ordinatias en el ámbito penal (prin. cipalmente, claro está, el Código penal) ofrecen una discrepancia de origen. Mientras que el Código proviene de un régimen autoctático (no obstante su raigambre liberal, algunas regias introducidas en 1944 desdibujan tal raigambre), la Constitución sienta las bases de un régimen democrático. A pesar de las parciales reformas habidas en el período de transición politica a que antes nos hemos referido, esa discrepancia de origen es todavía perceptible en ciertos aspectos. De ahí la necesidad de una interpretación que por vía hermenéutica sea capaz de superar tales discrepancias y adecuar la normativa penal a las directrices de la Constitución actualmente vigente. ${ }^{4}$

Otra cosa es que, además, la Constitución sirva de vinculación normativa de la que partir para el legislador ordinario. Desde el punto de vista de la Teoría de la legislación se ha destacado ${ }^{5}$ que esa vinculación tiene un doble sentido: negativo, en cuanto a la posibilidad de que el Tribunal Constitucional declate anticonstitucionales aquellas leyes que contravengan la Constitución; positivo, en cuanto a la exigencia de que sean promulga* das las leyes que la propia Constitución requiere para su desarrollo.

En relación al problema de conciliación de la normativa ordinaria con la Constitución, antes expuesto, conviene indicat que el Tribunal Supremo ha seguido ya ese criterio, al menos en algún ámbito jurídico. Así, una reciente sentencia del citado Tribunal referente a una multa gubernativa impuesta por la Dirección General de Seguridad en febrero de 1972 por haber participado en una manifestación ilegal, establece que el principio de aplicación realista que consagra el artículo 3 del Código civil obliga a considerar anuladas todas las sanciones gubernativas de carácter político impuestas en el anterior régimen y que se hallen actualmente pendientes de revisión ante los Tribunales. ${ }^{6}$ El artículo 3 del Código civil dispone en su primer apartado lo siguiente: «Las normas se interpretarán según el sen*

4. Vid. para la problemática semejante surgida en Italia, Stella, «La teoría del bene gituridico e i c.d. fatti inoffensivi conformi al tipos, Rivista italiana di Diritto $e$ Procedura Penale 1 (1973), pp. 36-37. Matinucci, Il reato come azione (Milano, Giuff́rè, 1971), pp. 183 y ss, También, entre nosotros, para la situación previa a la Constitución de 1978, pero con affrmaciones de valor genetal: Vives Antón, «Reforma política...», op. cit., pp. 105 y ss.

5. Noll, Gesetzgebungslebre, Reinbek bei Hamburg, tomo I (Hamburgo: Ro. wohlt, 1973), p. 104. p. 27.

6. Según noticia de prensa publicada en «El País», de 20 de junio de 1979, 
tido propio de sus palabras, en relación con el contexto, los antecedentes históricos y legislativos y la realidad social del tiempo en que han de ser aplicadas, atendiendo fundamentałmente al espiritu y finalidad de aquéllas.» Pues bien, el Tribunal Supremo argumenta que las citadas sanciones «respondieron a unos objetivos y legalidad que son incompatibles con los que constituyen el fundamento de la actual organización jurídico-política del Estado español, dotado de una Constitución que lo configura corno un Estado social de Derecho basado en principios democráticos, opuestos y superadores de los que sirvieron de justificación legal a dichas sanciones».?

\section{FUNCIONES DE LA CONSTITUCION EN EL AMBITO PENAL}

Una teferencia a las tareas que cabe derivat de la Constitución en el ámbito penal y a las funciones propias del Detecho penal nos servirá para enmarcar más concretamente esta cuestión.

Si partimos de considerar el Derecho penal como aquella parte del Ordenamiento jurídico que conmina con penas determinadas conductas consideradas como delitos y asigna medidas de seguridad a presupuestos de peligrosidad criminal, habrá que convenir que resulta necesatia la integración en el ordenamiento jurídico-penal de aquellas reglas constitucionales que de algún modo tienen que ver con los presupuestos (delito y peligrosidad criminal) o consecuencias (pena y medida de seguridad) propios del Derecho penal. ${ }^{8}$ En particular, los artículos 1, 9, 10, 15, 24, 25, 45 y 46 (entre otros mauchos) tienen una especial relevancia para el Derecho penal. Entre las funciones que pueden extraerse de la Constitución en el ámbito penal cabe enumerar las siguientes:

a) Una incidencia directa en la práctica, en los supuestos concretos que se presenten ante los tribunales. ${ }^{9} \mathrm{La}$ jurisprudencia debe tener en cuenta lo dispuesto en la Constitución a los efectos de aplicarlo directamente o de interpretar a la luz de la misma los preceptos ordinatios que requieran de una adecuación hermenéutica en base al texto constitucional. El artículo 9 de la propia Constitución declara sujetos a los poderes públicos a la Constitución y al resto del ordenamiento jurídico (apartado primero) y garantiza la jerarquía normativa (apartado tercero). Así, las

7. Según transcripción de la noticia de prensa citada en la nota anterior.

8. Ciertamente el sistema binario está actualmente en crisis, pero baste aquí apuntat esa situación.

9. Vid. Vives Antón, op. cit., pp. 110 y ss. 
disparidades entre el texto constitucional y las normas ordinarias deberán resolverse a favor del primero. Por ejemplo, en el artículo 24 de la Constífución se reconoce expresamente la presunción de inocencia; por otra parte, el artículo 483 del Código penal establece que «el reo de detención ilegal que no diere razón del paradeto de la persona detenida o no acreditate haberla dejado en libettad será castigado con la pena de reclusión mayor» (superior incluso a la prevista en el artículo 407 para el homicidio: teclusión menor). Una disposición semejante en relación con el delito de rapto ha sido erradicada recientemente del Código penal. Pues bien, dicho artículo 483 no se compadece con el precepto constitucional del artículo 24 antes citado, aun cuando se entienda éste en un sentido meramente procesal en relación a la prueba, pues también el «acreditar» a que hace refetencia el attículo 483 del Código penal invierte la carga de la prueba.

b) Una función de orientación politico-penal. De la Constitución cabe derivar propuestas de politica penal a tener en cuenta por la legislación futura. Así, el artículo 45 prevé el establecimiento de sanciones penales en los términos que la ley fije con el fin de proteger y mejorar la calidad de la vida y defender y restaurar el medio ambiente. Asimismo, el artículo 46 afirma que la ley sancionatá los atentados contra el patrimonio histórico, cultural y artístico de los pueblos de España. Más arriba nos hemos referido a este aspecto "positivo», de vinculación del legislador ordinario a la Constitución, frente al «negativo», que posibilita la declaración de inconstitucionalidad por parte del Tribunal Constitucional de aquellas leyes que contravengan la Constitución. Por lo demás, con la expresión "política penal» queremos indicar la política que fundamentalmente a través de las penas realiza el Estado. Nótese que no es equivalente a «política criminal», que tiene un ámbito más amplio, ${ }^{10}$ sino que constituiria en todo caso una parcela de ésta.

Pero además de las proptrestas expresas en la Constitución en materia de política penal, ésta deberá orientarse atendiendo también a criterios más genetales explícitos o implícitos en la Constitución. Así, del artículo 1 (en cuyo primer apartado se declara que «España se constituye en un Estado social y democrático de Derecho, que propugna como valores superiores de su ordenamiento jurídico la libertad, la justicia, la igualdad y el pluralismo político»), de los artículos 9 y 10 , del 14, del rango de los bienes jurídicos a que se alude a partir del artículo 15, de las propias disposiciones sobre las penas (artículos 15 y 25) cabe derivar también pro-

10. Vid. Brícola, «Política Criminal y Derecho Penal», Revue Internationale de Droit Pénal (1978), p. 105. Vid. también la presentación de Cobo del Rosal de la nueva tevista Cuadernos de politica criminal, 1 (1977). 
puestas de política penal, independientemente de que quepa acudir directamente a tales preceptos a los efectos indicados en el apartado anterior.

c) De los aspectos que acabamos de ver, es posible asimismo derivar una función doctrinal que puede a su vez tener repercusión en la práctica. La Constitución permite la elaboración de posturas doctrinales, en relación con la interpretación de la ley, la teoría del delito, la teoría de la pena, etc., como más adelante veremos.

Esta remisión a la Constitución viene a explicitar en definitiva a nivel formal constitucional la conexión subyacente entre Derecho penal y organización social.

\section{FUNCIONES DEL DERECHO PENAL}

Se suele asignar al Derecho penal una función básica de protección de bienes jurídicos." Tales bienes tienen muy diverso carácter, pero por considerarios imprescindibles para la vida social alcanzan la protección penal. Esa protección va referida a los bienes más fundamentales (vida, libertad, honor, etc.), pero además los protege: frente a los ataques más intolerables. Tales bienes jurídicos pueden clasiffarse en:

a) Bienes de cafácter genetal: p. ej.: exario público, orden público, etcétera.

b) Bienes individuales: vida, honor, etc.

c) Bienes institucionalizados: seguridad del tráfico, salıd pública, etcétera (constituyen como una bartera previa para la protección de los bienes «genuinos» que realmente importan: vida, integridad física, etc.).

Aunque normalmente suelen tenerse en cuenta sólo los dos primeros términos de esta clasificación, la «institucionalización» de bienes jurídicos va in crescendo, por lo que me parece relevante destacar esta clase de bienes que ocupan una posición «intermedia».

Esa función básica de protección de bienes jurídicos se realiza a través de un proceso psicológico de motivación inbibitoria, ${ }^{12}$ de manera que el

11. Vid. por todos, Rodríguez Mourullo, Derecho penal. Parte General, tomo I (Madrid: Civitas, 1977), pp. 18 y ss.

12. Cfr. en particular Gimbernat Ordeig, «¿Tiene un fututo la Dognática jutídico-penal?", pp. 64 y ss., en Estudios de Derecho Penol (Madrid: Civitas, 1976). Muñoz Conde, Introducción al Derecho Penal (Barcelona: Bosch, 1975), pp. 50 y ss. 
individuo evite la realización de conductas que atenten a los bienes jurídicos. Supone en realidad un último recurso de motivación, pues normalmente el individuo habrá internalizado a través de otros mecanismos (educación, etc.), el respeto a tales bienes. Esta tunción de motivación, es, pues, instrumental respecto a la antes indicada de protección de bienes jurídicos.

Junto a las dos funciones anteriores, no cabe desconocer que de hecho el Derecho penal cumple también, como señala Stratenwerth ${ }^{13}$ una función psicológico-social: su aplicación sublinna sentimientos de venganza que de no existir el Derecho penal podrían conducir a situaciones de reacción privada $o$ de linchamiento. Incluso el indicado autor ${ }^{54}$ llega a afirmar la posibilidad, fundamentada en tazones sociológicas y de psicología profunda, de que la sociedad misma «necesite» en alguna medida el delito para, a través de la lucha contra el mismo, asegurar normas sociales y con ello lograr también el aseguramiento de la propia sociedad. ${ }^{15}$

Esa función psicológico-social de sublimación de sentimientos de venganza sólo se alcanzaría a través de la aplicación del ordenamiento jurídicopenal, lo mismo que para la función motivadora inhibitoria antes vista no basta la mera conminación de una pena en la ley, sino la efectiva aplicación de ésta. En este sentido la aplicación del ordenamiento jurídico-penal serviría para sublimar conflictos que tengan una trascendencia social de especial gravedad.

Quizá habría que matizar que según la clase de delito cometido primarían o bien sentimientos de venganza propiamente dichos o bien deseos de mera satisfacción del perjuicio causado por el hecho delictivo. Se ajustaría así el Derecho penal a una de las funciones que se atribuyen al Derecho en general: Ia resolución de conflictos. En todo caso, conviene profundizar en las complejas cuestiones de la psicología social para un mejor conocimiento de esa función psicosocial y para una más correcta política penal. A mi juicio, habría al menos que distinguir de entrada dos grupos de personas: la víctima o sus allegados (si la hubo) y los ciudadanos no directamente afectados.

13. Strafrecht, Allgemeiner Teil, tomo I (Berlin: Carl Heymans, 1976), p. 28.

14. Op. y lugar citados en nota anterior.

15. Diferente, por tanto, será una problemática sobre la que conviene Ilamar brevemente la atención: se trata de que desde determinadas instancias y a través de un «laisser faire» en hechos delictivos se exacerban los sentimientos de seguridad de los ciudadanos con motivo de contiendas políticas o electorales y con objeto de canalizar tales sentimientos en favor de una u otra opción. Aquí no se trataria ya del fenómeno apuntado por Stratenwerth de asegurar normas sociales luchando contra ef delito, sino de pervertir el contenido mismo de la libre opción personal, base de una sociedad democrática. Lo mismo habría que decir de una manipulación informativa de tales hechos. 
No parece que los efectos sobre ambos 'grupos sean idénticos. La víctima o sus allegados sublimarian tensiones de venganza privada o deseos de satisfacción pot sí mismos del mal causado por el delito. Los ciudadanos no directamente afectados por el delito sublimarían sentimientos de inseguridad-agresividad o de satisfacción colectiva. Aun no estando implicados directamente, sus sentimientos de propia seguridad si resultan sensibilizados y quedan únicamente satisfechos por medio de la aplicación de la ley penal. ${ }^{16}$ Cierto que esa sensibilización dejenderá también de la clase de delito que se haya cometido. ${ }^{17}$

En todo caso, el hecho de que en ocasiones el perjudicado se plantee la utilización de unos u otros procedimientos que le ofrece el Ordenamiento jurídico como mejor modo de satisfacer sus expectativas o incluso llegue a acudir al arreglo privado (piénsese en los supuestos de cheque en descubierto, ciertas defraudaciones, etc.), debería hacet meditar sobre esta función de resolución de conflictos, que no tiene por qué ser exclusiva del Derecho privado. ${ }^{18}$

Algunos autores, desde diversas perspectivas ideológicas y acentuando el punto de vista sociológico, ${ }^{19}$ consideran al Derecho penal como un sistema de control social caracterizado por la imposición de las sanciones jurídicas más graves. Hay que tener en cuenta que esta consideración de sistema desde el punto de vista sociológico incluiría una serie de objetos de conocimiento (como normativa procesal, administrativa, de organización de ciertos «operadores del Derecho» es decir, jueces, funcionatios de policía, etc. ${ }^{20} \mathrm{y}$ otros) que no son abarcados por el Derecho penal en sentido estricto, sino por otras ciencias penales o que formatían parte de una «ciencia penal global». ${ }^{2 t}$

16. Respecto a un posible efecto de autosatisfacción distanciadora, vid. el attículo de Bustos Ramírez y Hormaxábal Mallaré en este mismo número de Papers.

17. Cfr. sobre agresividad y seguridad, Alexander Mitscherlich, La idea de la paz y la agresividad bumano (Madrid: Taurus, 1971), pp. 45 y ss. Vid. también el prólogo de Castilla del Pino en la mista obra.

18. Cfr. Díez Picazo, Experiencias juridicas y Teoria del Derecbo (Batcelona: Atiel, 1973), pp. 84 y ss.

19. Entre otros, cabe citar a Batatta, Philippe Robert y Hassemer. Vid. por todos Hassemer, «Das Strafrecht im System der sozialen Kontrolle», pp. 45 y ss., en $\mathrm{Ha}$ ssemer y Lüđersen, Sozialwissenschaiten im Studium des Rechts, Band III, Strafrecht (München: C. H. Beck, 1978).

20. Segín terminología acuñada por Treves, Introducción a la Sociología del Derecbo (Madrid: Taurus, 1978), pp. 174 y ss.

21. Una muestra de esta conccpción del Derecho penal en un sistema de con. trol social puede verse de una manera más amplia en otros trabajos que aparecen en esta misma obra. 


\section{LO EXPLACITO Y LO IMPLICITO EN LA CONSTITUCION}

Antes de pasar a la consideración de algunos problemas en telación a la conexión entre Derecho penal y Constitución, es necesario destacar una cuestión de orden metodológico ya apuntada antes. En unas ocasiones, la Constitución mostrará de una manera expresa, bien directa, bien indirectamente, cuál es el criterio a seguir. En otras, ese criterio habrá que deducixlo por no aparecer expresamente. Con ello quiero destacar la diferencia entre lo explícito y lo implícito en la Constitución, aplicando conocimientos que nos ha facilitado la teoría del lenguaje y que se han mostrado fecundos. En particular, la semántica y la pragmática ${ }^{22}$ ofrecen criterios metodológicos al jurista, que en ocasiones ya se usaban un tanto intuitivamente (recuérdese en telación al sentido de la expresión en las injurias las diversas clasificaciones en atención al animus del sujeto: corrigendi, iocan$d i$, etc.), y que, junto a otros, pueden ayudar en la tarea de la interpretación y de la concreción de la norma. Nótese que el lenguaje es el instrumento de expresión de la ley. ${ }^{23}$

A título de ejemplo: aparece expresamente abolida la pena de muerte, salvo lo que puedan disponer las leyes penales militares para tiempos de guerra, según lo dispuesto en el artículo 15 , inciso final. No aparece reconocida en la Constitución explícitamente la función de prevención general de las penas, mientras que el artículo 25 sí se refiere a la función de prevención especial cuando establece que «las penas privativas de libertad y las medidas de seguridad estatán orientadas hacia la teeducación y teinserción social» (apartado 2) ${ }^{24}$ Sin embargo, sí cabe derivar la prevención general de la propia Constitución, teniendo presente las limitaciones que ésta misma prevé (en particular el principio de justicia del artículo 1, la prohibición de penas o tratos inhumanos o degradantes del artículo 15), la alusión al «sentido de la pena», como uno de los criterios de limitación de los derechos del condenado, en el artículo 25 apartado segundo, y las propuestas de política penal de los artículos 45 y 46 . Ello no quiere decir que la prevención general esté sujeta sólo a los límites antedichos. Por lo demás, el propio concepto de prevención general es susceptible de cierta

22. Vid. Viehweg, «Rhetorik, Sprachpragmatik, Rechstheorie», pp. 717 y ss,, en Recht und Gesellschaft, Festscbrift für Helmut Schelsky zum 65. Geburtstag (BerIin: Duneker \& Humbloz, 1978).

23. Entre nosotros vid. en general: Capella, El Derecbo como lenguaje (Barcelona: Atiel, 1968). Díez Picazo, Experiencias juridicas... op. cit., pp. 102 y ss., pp. 251 y ss. En relación con el estructuralismo: Hernández Gil y otros, Estructuralismo y Derecho (Madrid: Alianza, 1973). Acerca de la pragmática: Sánchez de Zavaia, Indagaciones praxiologicas, tomo I (Madrid: Siglo XXI, 1973).

24. Vid. al respecto el trabajo de Córdoba Roda en esta misma obra. 
relativización en función de qué círculo de sujetos puede conneter ciertos delitos (piénsese en los delitos especiales en sentido propio) o qué limitaciones, por el propio tenor de la conducta descrita, imposibilitan que ésta pueda ser cometida de hecho por el común de los ciudadanos (piénsese en cierta clase de delincuencia económica), aunque no se dé una restricción formal a un determinado círculo de sujetos.

\section{LEY PENAL: EL PRINCIPIO DE LEGALIDAD $Y$ LA ANALOGIA «IN BONAM PARTEM»}

Una cuestión de gran interés y que en la doctrina no resuita pacífica hasta el momento es la referente al principio de legalidad en los aspectos recogidos en el artículo 2 (en conexión con el 1) del Código penal y la posibilidad o no de conciliar el texto de dicho artículo con la admisión de la analogía in bonam partem o favorable al reo. La Constitución puede ofrecernos base suficiente para solventar las dificultades hasta ahora existentes.

Sabido es que el principio de legalidad, aparte de ciertos antecedentes. más o menos discutidos, ${ }^{25}$ surge como garantía política en la época de la Ilustración. Formulado por Beccaria en tal sentido, aparece, por una parte, como reacción frente a intervenciones arbitrarias de los poderes públicos $y$, por otra, expresa la filosofía política rousseauniana. ${ }^{26}$ Unicamente las leyes pueden decretar las penas de los delitos, únicamente el legislador, que representa a toda la sociedad unida por el contrato social, puede establecerlas. No tardó en encontrar su plasmación política en las diversas constituciones. Más adelante Feuerbach acentúa otro sentido vinculado a su teoría de la pena como coacción psíquica, de manera que los ciudadanos se inhiban de cometer delitos; para ello es necesario que en la ley aparezcan descritos el delito y la pena, pues sólo así es posible saber qué conductas están sujetas a tal coacción y en qué consiste ésta. A partir de la elaboración del concepto de "tipo» por Beling suelen añadirse las exigencias de claridad y precisión ${ }^{27}$ en la descripción de las acciones punibles.

Esta rápida síntesis servirá para centrar el problema. En base al pri-

25. Cfr. por todos: Rodríguez Mourullo, «Legalidad (principio de)», pp. 882 y ss., en Nueva Enciclopedia Jurídica Seix, t. XIV (Barcelona: Seix, 1971) y del mismo autor, Derecbo penal..., op. cit., pp. 58 y ss.

26. Vid. Cerezo Mit, Curso de Derecho Penal Español, Parte General, t. I (Madrid: Tecnos, 1976), p. 155.

27. Vid. Rodríguez Mourullo, Derecbo penal..., op. cit., pp. 59 y 60. 
mado del principio de legalidad como garantía para el ciudadano frente al poder punitivo, la doctrina dominante afirma que, si bien la analogía in malan partem (fundamentadora o agravatoria de la responsabilidad criminal) está prohibida, la analogía in bonam partem debe admitirse. ${ }^{28}$ Frente al criterio anterior, Córdoba sostiene que el artículo 2 del Código penal prohíbe toda analogía. ${ }^{29}$ En efecto, el obstáculo principal para la admisión de la analogía in bonam partem está en el artículo 2, que dice así: "En el caso de que un Tribunal tenga conocimiento de algún hecho que estime digno de represión y que no se halle penado por la ley, se abstendrá de todo procedimiento sobre él y expondrá al Gobierno las razones que le asisten para creer que debiera ser objeto de sanción penal (párrafo $1 .^{\circ}$, que respondería al principio de legalidad como garantía para el ciudadano). Del mismo modo (sigue el pátrafo $2 .^{\circ}$, que interesa especialmente aquí), acudirá al Gobierno exponiendo lo conveniente, sin perjuicio de ejecutar desde luego la sentencia, cuando de la tigutosa aplicación de las disposiciones de $\mathrm{la}$ ley resultare penada una acción u omisión que, a juicio del Tribunal, no debiera serlo, o la pena fuere notablemente excesiva, atendidos el grado de malicia y el daño causado por el delito.» Para salvar dicho obstáculo, se argumenta en general que el Código prevé en otros artículos la posibilidad de la admisión de la analogía favorable al reo, en particular en el artículo 9 circunstancia décima, que admite como atenuante ucual. quiera otra circunstancia de análoga significación que las anteriores». ${ }^{30}$ Pero la «rigurosa aplicación de las disposiciones de Ia ley», indica Córdoba, ${ }^{31}$ comporta ya los casos previstos por Ia ley, como el de Ia circunstancia décima del artículo 9.

En definitiva, el artículo 2 en su párrafo segundo supone una previsión legal que dispone la subordinación del tribunal penal al poder legislativo y afirma la autoridad de la ley en todo caso..$^{32}$ De ahí, que se haya

28. En este sentido, entre otros: Muñoz Conde, Introducción..., op. cit., pp. 151-2.

29. Córdoba Roda: en Córdoba Roda, Rodríguez Mourullo, del Toro Marzal y Casabó Ruiz, Comentarios al Código penal, t. I (Barcelona: Atiel, 1971), p. 59.

30. Así, Muñoz Conde, Introducción..., op. cit, p. 152, aun admitiendo que el argumento de Córdoba Roda en relación al arcículo segundo «es ciertamente agudo e inatacable». Rodríguez Devesa propugna la superación de la distinción entre analogía in bonam partem e in malan partem por la de permitida y prohibida: «Está permitida tođa analogía que no sea fundamentadora de delitos, penas, causas de agravación o medidas de seguridad. Probibida, por el contrario, la analogía que conduzca a resultados en oposición al principio de legalidad (Derecbo Penal español, parte general (Madrid: Rodríguez Devesa, 1976), p. 206.

31. Op. y lugar citados en nota 29 .

32. Por otra parte, tal autoridad de la ley, evidentemente, en el contexto politico del régimen anterior no podía basarse en la elaboración y aprobación democtática de la misma, es decir, no respondía siquiera al postulado de filosoffa política tousseau- 
intentado otro camino para resolver el problema: esta otra vía consistiría en tratar de conciliar la expresión «rigurosa aplicación de las disposiciones de la ley» con la analogía, es decir, en afirmar que la indicada expresión «no es contradictoria con Ia analogía». ${ }^{33}$ Clato que la aceptación de esta vía llevaría a considerar la atxalogía como una forma de aplicación de la ley tanto si dicha analogía es favorable como si es contraria al reo y a reducir la analogía in malam partem a un principio no expresado en la ley. Como explícitamente se teconoce: ${ }^{34}$ «Descartado el artículo 2 como base de la prohibición de analogía, no existe ningún otro precepto en nuestro Derecho penal que la formule expresamente; sólo queda una posibilidad, y es la de considerar la exclusión de la analogía in malam partem un postulado político-criminal de nuestro derecho punitivo, no formulado explícitamente, pero acogido pot el inequívoco espíritu liberal del Código penal.»

Hemos visto que necesidades de la práctica judicial y de política penal han llevado a argumentar, ftente al texto del artículo 2, pátrafo segundo del Código penal, básicamente de una doble manera: o bien reconociendo su explícita prohibición de la analogía, pero acudiendo a otras declaraciones del propio Código para atenuar la «totalidad de dicha prohibición», en favor de la acogida de la analogía in bonam partem, mediante un criterio sistemático; o bien removiendo el sent do hasta ahora aceptado del propio artículo 2. La Constitución creo que otrece base suffiente para superar los obstáculos del artículo 2, párrafo sęundo, sin necesidad de consecuencias indeseables y conciliando así las necesidades antes aludidas y el respeto a la ley.

$\mathrm{Si}$ nos atenemos a lo que la propia Constitución dispone, observamos que en el artículo 9, apartado tercero, se establecen una serie de garantías jurídicas: «La Constitución garantiza el princin̨io de legalidad, la jerarquía normativa, la publicidad de las normas, la irretroactividad de las disposiciones sancionadoras no favorables o restrictivas de derechos individuales, la seguridad jurídica, la responsabilidad y la interdicción de la arbitrariedad de los poderes públicos.» Respecto a la exigencia de lex praevia en el ámbito penal, concreta el artículo 25 , apartado primero: «Nadie puede ser condenado o sancionado por acciones u omisiones que en el momento de producirse no constituyan delito, falta o infracción administrativa, según la legislación vigente en aque!l momento.» Pues bien, es de destacar el sen-

niana que, como se ha indicado más arriba, estaba ex la base de la formulación del principio de legalidad por Beccaria; aunque to displesto en el párrafo segundo del artículo 2 fue ya introducido por la reforma de 1850 al Código de 1848 .

33. Así Mir Puig, Introducción a las bases del Ilerecho Penal (Barcelona: Bosch, 1976), p. 320.

34. Ibidem. 
tido de garantía para los ciudadanos que el propio artículo 9, apartado tercero, explícita con toda clatidad: «La Constitución garantiza...» Y entre lo que garantiza a los ciudadanos en ese apartado está el principio de legalidad, la seguridad jurídica y la interdicción de la arbitrariedad de los poderes públicos. Con ello quedaría claramente excluida la analogía in malam partem y consecuentemente aceptada la favorable al reo. Ese criterio garantizador permite salvar a nivel constitucional los obstáculos que ofrecen las leyes ordinarias. Además, en el artículo 1, apartado primero, de la Constitución se aftrma que «España se constituye en un Estado social y democrático de Derecho, que propugna como valores superiores de su Ordenamiento jurídico la libertad, la justicia, la igualdad y el plutalismo político». De esta fundamental declaración y, en particular, de la consideración de la justicia y la igualdad como valores superiores del Ordenamiento jurídico cabe extraer argumentos en favor de la analogía in bonam partem. En efecto, si el sentido de gatantía del apartado tercero, del artículo 9 de la Constitución excluye ya la analogía in malam partem, el contraste entre dicho apartado y la apelación a los valores de justicia y de igualdad (en particular al primero) del artículo 1, apartado primero, de la propia Constitución, permitirian basar en los mismos los criterios que regirían la analogía in bonam partem. Con ello se mantendría, por una parte, un límite infranqueable, por garantizarlo así el apartado tercero del attículo 9 (la prohibición de la analogía in malam partem), mientras que, por otra, se daría cabida a la entrada en juego de tales valores de justicia y de igualdad. Supondría ésta una «tercera vía» de superación de los obstáculos ofrecidos por el artículo segundo del Código penal, la cual tendería a salvar las dificultades por vía hermenéutica de apelación a la Constitución que encuentra la analogía in bonam partem en el texto del Código.

La riqueza de consecuencias a que conducen estas consideraciones sobre los artículos 9, apartado tercero, y 1, apartado primeto, de la Constitución, no se reduce al ámbito peral, ni tampoco, dentro de éste, a la cuestión de la analogía. Baste, por ejemplo, indicar que en relación a supuestos de "delito masa» y de "delito continuado» se pondrían mantener las ventajas que el criterio de justicia puede comportar, mientras que desaparecerían las desventajas por no poder superarse los límites que el apartado tercero del artículo 9 garantiza. ${ }^{35} \mathrm{Y}$ así en muchas otras cuestiones.

Por otro Iado, el interés que ofrece el planteamiento expuesto para una teoría de la interpretación de la ley es algo que aquí sólo puede ser

35. Con to que quedarían salvadas aquellas preocupaciones que se expresan a veces en la doctrina: vid. p. ej., las manifestadas por Muñoz Conde, Derecho Penal, parte especial (Sevilla: Univ. Sevilla, 1976), p. 227. 
apuntado. En especial la ponderación entre lias garantías del principio de legalidad y de la seguridad jurídica y los valores de libertad, de justicia y de igualdad es algo que puede resultar enormemente fructífero. En otro sentido, la política jurídica en el futuro debe :ener presente tales garantías y tales valores. Igualmente resultará de interés para una teoría de la legislación.

\section{TEORIA DEL DELITO: PROTECCION DE BIENES JURIDICOS, PRINCIPIO DE CULPABILIDAD}

Se ha indicado más arriba, al tratar de: las funciones del Derecho penal, que éste cumple una función básica de protección de bienes jurín dicos. Un nuevo contexto jurídico-político expresado en una constitución democrática ha de suponer una nueva política penal respecto a la valoración de los bienes jurídicos, gradación entre liss mismos, determinación de cuáles no exigen o no merecen protección pe:zal, de cuáles otros sí la requieren, etc. Unos criterios a tener en cuenta pueden derivarse de la enu. meración de bienes que se hace a partir del artículo 15 de la Constitución: vida e integridad física y moral, libertad ideclógica y religiosa, libettad y seguridad personales, honot, etc. Aunque no se explicite la protección penal de los mismos ni se indique otro nivel de protección en el Ordenamiento jurídico, del rango que se otorga a los mismo:; podría deducirse un interés primordial en la protección de tales bienes. Por otra parte, y precisamente por este rango, no es necesario que se fo:mule expresamente que bienes como la vida y la integridad, por ejemplo, requieren protección incluso a nivel penal. No alcanza igual grado de protzcción la propiedad. Está teconocida en el artículo 33, dentro de la sección segunda del capítulo segundo del Título 1 , y no en la sección primera como los bienes antedichos, con lo cual no alcanza el reconocimiento que el artículo 53, apartado segundo, otorga a la sección primera (posibilidad de que Ios ciudadanos recaben la tutela de los derechos y libertades reconocidos en eila y posibilidad también del recurso de amparo). De alı́ que la sobreprotección actual de la propiedad en el Código penal deba atemperarse en el nuevo Código. Ello puede hacerse a través de tres vías: a) reajuste de las penas, a veces excesivas; $b$ ) reducción del casuismo (observable por ejemplo en la regulación de los delitos de estafa); c) exclusión de aquellos supuestos de inne. cesaria protección (p. ej.: la puesta en peligro de los bienes en el artícutlo 340 bis b), que los equipara a la vida).

Por otra parte, la Constitución establece la previsión de sanciones pe- 
nakes en algunos artículos. Así, en el artículo 45 y en relación a la protección de la calidad de la vida y del medio ambiente se prevé el establecimiento de «sanciones penales o, en su caso, administrativas, así como la reparación del daño causado». También en el artículo 46 se indica que la ley penal sancionará los atentados contra el patrimonio histótico, cultural y artístico de los pueblos de España. Es decir, se establecen propuestas de política penal que deben desarrollar las leyes ordinarias para proteger los bienes indicados, que, a diferencia de los que hemos visto antes, se entiende que requieren por parte del legislador una expresa declaración de protección, aun cuando alguno de los supuestos pudiera ya tener cabida en la regulación actual: piénsese en los delitos contra la salud pública previstos a partir del artículo 341 del Código penal, de un lado, y, de otro, en los artículos 561 (que castiga la destrucción o deterioro de pinturas, estatuas u otros monumentos públicos, de utilidad u ornato), 558 circunstancia quinta (daños en archivo, registro, museo, biblioteca, gabinete científico, institución análoga o en el Patrimonio Histórico-Attístico Nacional), y 563 bis a) (agravación de las penas cuando las cosas fueren de relevante interés histórico, artístico o cultural).

De lo dicho anteriormente cabría derivar un reconocimiento implícito o explícito por parte de la Constitución de la protección de bienes jurídicos por el Derecho penal. Ello, aparte de su interés para la política penal, supone una afirmación de enorme relevancia para la teoría de delito. Por un lado, el legislador debe atenerse al límite que supone el mandato constitucional, de manera que solamente aquellas conductas que supongan la lesión o la puesta en peligro de un bien jurídico o, al menos (como límite inferior insuperable) comporten por sí mismas efectivamente un peligro, merecen sanción penal. Por otro, la teoría del delito tiene una base constitucional para reafirmar el peso del liamado desvalor de resultado (es decir, el desvalor de afectación del bien jurídico).

Las consecuencias no paran ahí, pues de la protección de bienes juxídicos, como función reconocida a nivel constitucional, se derivan una serie de limitaciones tanto por lo que atañe al Libro I (disposiciones generales) como al Libro II (delitos y sus penas) del Código penal. Así, y a título de ejemplo, el Ilamado «delito imposible» que el Código reguta en el párrafo segundo del artículo 52 y las conductas recogidas en el artículo 4 (en conexión con el 3) quedarían afectadas por dichas limitaciones (siempre teniendo presente el criterio de nivel «mínimo» expresado antes).

Vale la pena añadir que el propio artículo 45 nos ofrece también una base constitucional para el principio de intervención mínima, ${ }^{36}$ confirmando

36. En expresión de Muñoz Conde, Introducción..., op. cit., pp. 59 y ss. 
el carácter fragmentario del Derecho penal. Al distinguir entre sanciones penales y sanciones administrativas sienta un principio que a partir de ahora no será una mera exigencia de política jurídica, sino que encontrará su fundamento en ese reconocimiento del artículo 45, aun cuando éste en principio establezca esa distinción respecto a las sanciones en relación a la protección de la calidad de la vida y del medio ambiente.

Del teconocimiento de la garantía de la seguridad juridica en el attículo 9 de la Constitución y de la dignidad de la persona en el 10, cabría también extraer consecuencias de «teafirmación del principio de culpabilidad» ${ }^{37}$ de manera que cada cual responda de io que realmente hizo, pero no de lo que exceda de ello y no pueda serle: atribuido. La repercusión, por ejemplo, en los delitos sualificados por el resultado o en los delitos de sospecha vendría a colmar una aspiración latgamente sentida por la doctrina. Mucho más, si se atiende también al valot de justicia auspiciado por el artículo 1. También así se ofrecería un instrumento legal de tango constitucional para salvar los problemas que ciertos tipos penales presentan. La exigencia de seguridad jurídica como criteris político-penal resulta también clara y el legislador deberá tenerla presente en la redacción de los tipos.

Por último, importa subrayar simplemente la adquisición de rango constitucional del "principio del hecho». Y ello no sólo por la gatantía de la libertad ideológica (artículo 16), sino por la expresión concreta utilizada en el artículo 25, apartado primero: «....Nadie puede ser condenado o sancionado por acciones $u$ omisiones que...» $\mathrm{Ha}$ de existir siempre una acción u omisión, excluyéndose la punición de meras actitudes internas y el llamado Derecho penal de autor. Ese principio, sin embargo, puede ser desvirtuado por el legislador en la redacción da: los tipos; de ahí là gatantía que suponen la afectación del bien jurídico y el principio de culpabilidad.

\section{TEORIA DE LA PENA: LIMITES, PREVENCION Y FUNCION PSICOLOGICO-SATISFACTIVA}

La actitud de la Constitución en telación a la pena muestra también aspectos explícitos frente a otros implícitos.

Ante todo, cabe señalar la abolición de la pena de muerte, salvo lo que puedan disponer las leyes penales militares para tiempos de guerra, 1977).

37. Vid. recientemente Córcloba Roda, Culpabilidad y pena (Barcelona: Bosch, 
según dispone el artículo 15 . Este paso supone uno de los avances más deseados por todos los que consideran a la vida humana, incluida la de quien ha cometido delitos graves, un bien que no podia ser instrumentalizado a efectos penales.

En el propio artículo 15 de la Constitución se fijan además unos límites a las penas en general. Éstas no podrán ser inhumanas o degradantes, en clara referencia a lo dispuesto por el artículo 5 de la Declaración Universal de Derechos Humanos. Por lo demás, la prohibición de la tortura, que también aparece en el citado artículo de la Constitución, ba encontrado ya plasmación en el artículo 204 bis del Código penal. Esos límites de las penas están en conexión con la dignidad de la persona a la que se alude en el artículo 10 como fundamento (entre otros) del orden político y de la paz social.

Esta necesidad de establecer unos límites que toda pena debe guardar supone una concepción en la que la pena es vista como lo que es: un mal necesario para el mantenimiento de la vida social, mal que debe reducirse a lo estrictamente requerido para dicho mantenimiento. Esa concepción parece confrmada por la alusión al «sentido de la pena» que se hace en el artículo 25 apartado segundo como uno de los criterios limitadores de los derechos del condenado. Por consiguiente aqueilas penas privativas de libertad que por su duración pudieran considerarse inhumanas, estatían prohibidas por la Constitución. Se ha hablado al respecto de que las penas que exceden de doce o quince años merecerían tal consideración «ya que entonces parece que comienza el deterioro mental». ${ }^{38}$

Una segunda manifestación explícita de la Constitución se refiete a la orientación de las penas privativas de libertad: estarán orientadas, según el artículo 25 , apartado segundo, hacia la reeducación y reinserción social (al igual, por lo demás, que las medidas de seguridad). De un precepto semejante en la Constitución italiana (artículo 27, pátrafo tercero: "las penas no pueden consistir en actos contrarios al sentimiento de humanidad y deben tender a la reeducación del condenadon) ha extraído la doctrina de aquel país importantes consecuencias no sólo para la teoría de la pena, sino también para su incidencia en la práctica y en la teoría del delito. ${ }^{39}$ Pero aquí baste destacar el sentido humanitario pretendido y las limitaciones a que tal declaración está sujeta por la propia naturaleza de las penas privativas de libertad, que se cumplen en un medio bien distinto al socialmente

38. Barbero Santos, «La reforma penal española en la transición a la democracia», en Revue Internationale de Droit Pénal I (1978), pp. 63-64.

39. Vid. Btícola. «Teoría Generale del reato», en Novissimo Digesto Italiano, t. XIX, Torino (1973), pp. 81 y ss. 
normal, por la propia noción de reeducación y reinserción social, difícilmente apropiada para quienes no tuvieron previamente tal educación e inserción, por un lado, y, por otro, para quienes el delito cometido es justamente muestra de un ajuste a determinados «valores» sociales, así como de dudosa eficacia cuando el condenado tiene ya cierta edad. ${ }^{40}$

Frente a la explicitación de una función de prevención especial de las penas privativas de libertad en el artículo 25 de la Constitución, no aparece ninguna referencia explícita a la función de prevención general de la pena que, sin embargo y con las limitaciones a las que se ha hecho referencia más arriba al hablar de lo explícito y de lo implícito en la Constitución, cabe deducir de los límites a las penas del articulo 15, del «sentido de la pena» aludido en el artículo 25 y de las propuestas de política penal de los artículos 45 y 46 . Si se trata de proteget los bienes indicados en dichos artículos mediante sanciones penales es porque se otorga una función capaz de prevenir conductas atentatorias a tales bienes. Con ello se reconocería también, aunque no se haga una declaración explicita, la función de prevención general por medio de la amenaza de un mal, mal que no puede sobrepasar ciertos límites.

Unas últimas consideraciones sobre el tan discutido tema de pena y retribución. Aquí, como en muchas otras discusiones en el ámbito penal, las cuestiones de terminologia llevan muchas veces a dificultades de entendimiento. Si prescindimos de «etiquetas», que oscurecen en ocasiones el contenido de lo «etiquetado», y atendemos directamente a dicho contenido, podemos quizás aclarar mejor los problemas. Farece que no habría mayor dificultad en la estimación de que la pena e:i un mal. Tampoco habría dificultad en que debe ser proporcional al delio, atendida la culpabilidad. Si la pena cumple una función de satisfacción psicológico-social en relación a la víctima y sus allegados y a los ciudadanos en general, ${ }^{41}$ no se ve la razón de que no se tenga en cuenta ese efecto, llámesele retribución o como se quiera, junto a las funciones ya consideradas. ${ }^{42}$ En todo caso, tal satisfacción no debe superar los límites establecidos por el artículo 15 de la Constitución y debe tener bien presente el «valor superior» de justicia del artículo 1. Ello no quiere negar que incluso pueda prescindirse de la

40. Vid. para estas dificultades conceptuales y reales Córdoba Roda, en esta misma obra; Bergalli, ¿Readaptación social por medio de la ejecución penal? (Madrid: Instituto de Criminología (Iniv. Complutense, 1376), pp. 33 y ss.

41. Vid. lo dicho más arriba en Funciones del Derecho penal.

42. Respecto a la combinación entre las diversas funciones de la pena y los momentos de conminación, aplicación y cjecución, vid. Roxin, «Sentido y límites de La pena estatal», pp. 11 y ss., en Problemas básicos te Derecbo penal (traducción y notas por Luzón Peña), (Madrid: Reus, 1976). 
pena: en unos casos porque ya se entiende que el autor ha sido afectado por las consecuencias de su conducta $y$, por tanto, el efecto indicado ya se da (piénsese en quien causó imprudentemente un accidente de circulación que le ha afectado a él personalmente o a alguno de sus allegados); en otros, porque primen consideraciones de política criminal (por ejemplo, en ciertos tipos de delitos cometidos por delincuentes juveniles). No se trata, pues, de una retribución en sentido kantiano; no se requiere, evidentemente, que el solitario de una isla tenga que cumplir la pena im. puesta antes, porque en ese ejemplo ya no se da ninguna relación social, no hay ya sociedad. Peto sí que se tenga en cuenta ese efecto psicológico destinado a la resolución de conflictos sociales y tan perceptible o más que el de prevención general. Y ésta no tiene por qué superar los límites del criterio antedicho, porque entonces se mostraría como excesivamente cela. dora de bienes jurídicos que no requieren, en el sentir social, sanciones tan graves; sentir social, claro está, democráticamente plasmado en la ley y no sujeto al albur de coyunturales sentimientos.

\section{POSIBILIDAD DE UNA DOGMÁTICA PROGRESIVA}

El Derecho penal, como última ratio legis, pune sólo las conductas más intolerables socialmente y exige un cierto consenso al respecto. De ahí su vinculación a un cierto desarrollo democtático de la Constitución. Pero ésta ofrece ya puntos de vista para una dogmática progresiva que tenga presente la integración en el Derecho penal de las normas constitucionales, que responden a una visión político-jurídica más generosa y que, por tanto, son susceptibles de introducir avances notables respecto a un Código penal que, aun con las reformas recientemente introducidas, resulta deudor de un origen evidentemente distinto de la Constitución. En esta línea se ha querido esbozar aquí algunas propuestas como primera formulación de una problemática que requerirá en el futuro un esfuerzo continuado de profundización doctrinal, a la espera también de un nuevo Código penal que se atenga a las directrices ya perceptibles en la Constitución y en particular a lo propugnado por su artículo 1 .

Cierto que, como ha señalado Rodríguez Mourullo, ${ }^{43}$ «el mundo de Ios bienes jurídicos no forma un montón aromizado sino el orden social... de ahí que la significación de un determinado bien jurídico no se pueda

43. Rodríguez Mourullo, Derecbo penal..., op. cit., p. 20, acogiendo criterios de Welzel y Armin Kaufmann. Vid. también Bustos Ramírez, "Consideraciones en torno del injustom, en Nuevo Pensamiento Penal (1974), pp. 42 y ss. 
comprender considerándolo aisladamente, sino tan sólo contemplándolo en su interdependencia con el total orden social». En la medida en que ese orden social se ajuste a los valores de libertad, justicia, igualdad y pluralismo político, declarados valores superiores del Ordenamiento jurídico por el indicado artículo 1, apartado primero de la Constitución, se estará cumpliendo lo prescrito en la misma.

Por otra parte, en la medida en que no se pervierta el contenido de la democtacia, únicamente alcanzable en base a la efectividad de los indicados valores, se estatá cumpliendo asimismo con lo que reconoce el apartado segundo del propio artículo 1: «La soberanía nacional reside en el pueblo español, del que emanan los poderes del Estado.» Para ello xesulta imprescindible el respeto más profundo en todas aquellas manifestaciones que conforman la voluntad popular y, en particular, la transparencia y la veracidad en la formación y en la información, que están en la base de dicha voluntad.

La Constitución, pues, ofrece cauces apropiados para la plasmación de los valores básicos indicados. A ello deben ir también ditigidas una dogmática y una política penal que sean consecuentes con el texto constitucional.

\section{José María Escrivá}

Seminario de Derecho Penal

Facultad de Derecho

Universidad de Barcelona

Barcelona 